\title{
Orally disintegrating vardenafil tablets for the treatment of erectile dysfunction: efficacy, safety, and patient acceptability
}

This article was published in the following Dove Press journal:

Patient Preference and Adherence

12 April 201 I

Number of times this article has been viewed

\section{Roger Green' \\ Rodney W Hicks ${ }^{2}$ \\ 'The University of Arizona College of Nursing, Tucson, AZ, USA; ${ }^{2}$ Nurse Researcher and Safety Consultant, Lubbock, TX, USA}

Background: Erectile dysfunction (ED) is a well-documented medical condition that is expected to increase significantly over the next several decades, especially as men live longer and the prevalence of diabetes and cardiovascular diseases increase. Pharmacology agents are often the first line treatment approach. Newer solid dosage forms, known as orally disintegrating tablets (ODT), are now available as one treatment option.

Objectives: To review the drug delivery mechanisms of ODTs in general and to review safety and efficacy of vardenafil ODT (a PDE-5 inhibitor) as a treatment option for management of ED.

Method: Literature reviews were performed of pharmaceutical dosage forms and the POTENT I ( $\mathrm{n}=358$ subjects) and POTENT II ( $\mathrm{n}=337$ subjects $)$ studies that investigated vardenafil ODT.

Results: Vardenafil ODT has been successfully used in multiple age groups and in multiple settings with men from various ethnic backgrounds. Efficacy of vardenafil ODT, as measured using the International Index of Erectile Function (IIEF-EF) and from the Sexual Encounter Profile (SEP) was significantly greater than placebo $(P<0.0001)$ at 12 weeks. Safety profiles were similar to film-coated dosage forms with no patient deaths reported.

Conclusion: Vardenafil ODT offers a convenient, ready-to-use approach for combating ED. Safety concerns are similar to other PDE-5 inhibitors and practitioners should counsel patients accordingly.

Keywords: orally disintegrating tablets, vardenafil, erectile dysfunction

\section{Introduction}

Both the National Institutes of Health and the American Urological Association define erectile dysfunction (ED) as the inability to achieve, maintain, or sustain an erection firm enough for sexual intercourse. ED is a complex condition that negatively impacts men's self-esteem, quality of sexual satisfaction, and interpersonal relationships, and impedes in other quality of life areas. ${ }^{1}$ The etiology of ED is equally complex; increasing age, concomitant diseases (eg, cardiovascular disorders, hyperlipidemia, endocrine disorders, psychological disorders), obesity, prior surgeries (eg, prostatectomy) are well known causes. ${ }^{2}$ Other patient risk factors for ED include alcohol use, tobacco use, and illicit drug use. Pharmaceutical use is also a factor as many commonly used products contribute to ED (Table 1).

ED is recognized worldwide. The Massachusetts Male Aging Study (MMAS) from the United States provides estimates of ED. Authors of the original research reported that $8 \%$ of males in the fourth decade of life had ED and that burden increased to nearly $40 \%$ by the time males reached the age of 60 to 69 years. Worldwide, it is expected
Correspondence: Roger Green I 268 East Ramon Road \# 9, Palm Springs, CA 92264, USA

Tel + I 8I32207774

Email drrogergreen@aol.com 
Table I Common classes of drugs associated with erectile dysfunction

\begin{tabular}{ll}
\hline Drug class & Examples of specific drugs \\
\hline Antihypertensives & $\begin{array}{l}\text { Alpha-adrenergic agonists } \\
\text { Beta blockers (nonselective) } \\
\text { Calcium-channel blockers }\end{array}$ \\
Diuretics & Aldosterone antagonists \\
& Thiazide diuretics \\
Psychiatric agents & Benzodiazepines \\
& Butyrophenones \\
& Selective serotonin reuptake inhibitors \\
Cardiac glycosides & Tricyclic antidepressants \\
Steroid agents & Digitalis preparations \\
Neoplastic agents & \\
\hline
\end{tabular}

Note: Data from Hatzichristou DG, Pescatori ES. Current treatments and emerging therapeutic approaches in male erectile dysfunction. BJU Int. 200 I; Suppl 3:I I-I7. ${ }^{4}$

that nearly 322 million men will experience ED by the year 2025 , an upward trend that is associated with life longevity and increased prevalence of diabetes. ${ }^{3}$

Clinicians' understanding of ED has increased significantly over the past 20 years through better knowledge of the peripheral physiology of penile erections. ${ }^{4} \mathrm{ED}$ can be classified as either organic or psychogenic. ${ }^{5}$ Organic classifications include arteriogenic, cavernosal, or mixed; neurogenic; anatomic; and endocrinologic. Psychogenic classifications include generalized or situational. Causes of ED are not mutually exclusive. ${ }^{6}$

\section{Pathophysiology}

An erection is under control of the autonomic nervous system (ANS), but can also be stimulated or inhibited by central nervous inputs. ${ }^{7}$ Mechanoreceptors of the penis, through stimulation, elicit parasympathetic nerves of the ANS to relax in the walls of penile arterioles. Arousal also increases the release of nitric oxide from noncholinergic and nonadrenergic parasympathetic nerve endings in the arterial walls and sinusoid of the penile corpora cavernosa. Nitric oxide is a catalyst for the enzyme, cyclic guanosine monophosphate (cGMP). Its effect is noted in relaxing the smooth muscle, which reduces the resistance of the blood flow into the penis, thereby increasing the amount of blood flow into the corpora cavernosa. There is a corresponding inhibition of sympathetic nerves. The small arterioles leading to the cavernous sinuses contract and reduce blood flow. The smooth muscles regulating the blood vessels also contract. Removal of cGMP is accomplished with the enzyme phosophodiesteras-5 (PDE-5). Inhibition of PDE-5 decreases metabolism of cGMP, an action that increases smooth muscle relaxation and maintenance of the blood flow into the erect penis. ${ }^{8}$

\section{Pharmacology treatment options for ED}

First line pharmacology treatment options for ED are PDE-5 Inhibitors, with sildenafil, tadalafil, and vardenafil being the three most widely used. The US Food and Drug Administration approved the first PDE-5 inhibitor in 1998. This class of agents works by selectively inhibiting PDE-5; an action that increases and or preserves the cGMP levels in the penis. As a result, erections may last longer.

PDE-5 inhibitor products are intended for oral administration and are manufactured in solid dosage form. All of the PDE-5 inhibitor products are available as unscored, film-coated tablets and in a variety of strengths. Vardenafil, while available in a film-coated tablet, is the one product also available as an oral disintegrating tablet (ODT). Clinicians are encouraged to recognize characteristics of ODTs and incorporate that information when prescribing products with multiple dosage forms. The purpose of this article is to explore the benefits of ODTs in general and especially within the management of ED.

\section{Routes of administration}

According to the United States Pharmacopeia, tablets are solid dosage forms in which the active pharmaceutical ingredient (API) is blended with excipients and compressed into final form which, unless otherwise indicated, conveys the meaning of immediate release. This dosage form is generally intended for swallowing. Another dosage form, ODT, is meant for rapid disintegration within the mouth to provide dispersion before swallowing. ${ }^{9}$ In the European Pharmacopeia, this type of dosage form is known as orodisperse. ${ }^{10}$ Various other words (eg, rapid dissolving, rapid disintegration, mouth dissolving) convey the same intent and may be used by different manufacturers in marketing.

ODTs entered the market in the 1980s as an alternative to tablets or other conventional dosage forms (eg, capsules, lozenges, syrups, elixirs). ${ }^{11}$ There remains a continued interest for further ODT product development stemming from the need for noninvasive delivery systems, accurate dosing, and to facilitate patient compliance. ${ }^{11,12}$

\section{Patient factors}

Many patient factors make ODTs suitable, including impaired swallowing, inconvenience of swallowing large amounts of liquid, or pre-existing nausea. Dysphagia or difficulty swallowing is common in the general population, about $35 \%$ being affected at some point. ${ }^{12}$ Dysphagia increases in patients with advancing age or certain medical 
conditions (eg, cerebral vascular accident). Patients with advanced liver dysfunction may also find ODTs suitable, as these drugs avoid first pass effect.

\section{Drug property factors}

Characteristics of the API also contribute to the suitability of ODTs. Ideally, an ODT does not require water for administration; disintegrates within a few seconds $(<30)$; allows for high-drug loading; has no unpleasant after taste; is not affected by environmental conditions of humidity (hygroscopicity) or wide temperature variation; and is cost effective. ${ }^{11,12}$

Another important consideration is porosity. Faster absorption of water into an ODT tablet results in faster disintegration, a measure of tablet strength and structure. The ideal ODT has sufficient porosity and avoids becoming soft, friable, or unsuitable for packaging in blister packs. ${ }^{12}$ A related concept here is wetting time. The lower the wetting time, the faster the disintegration.

Final considerations of ideal ODTs must include the bioavailability and onset of action, two attributes more closely related to ODTs than the other solid dosage forms. As dispersion through saliva occurs, pregastric absorption also occurs. Decreased saliva may slow the rate of disintegration and may decrease bioavailability. ${ }^{11}$ Reductions in side effects from products with ODTs has also been reported. ${ }^{12}$ ODTs offer superior dosing accuracy compared with other oral forms such as liquids or elixirs.

Medications that require large amounts of liquid would not be suitable for ODT. Medications that have either short half-lives (those requiring frequent administration) or sustained-release formulation would also be unsuitable.

\section{Patient compliance and acceptance}

Patient compliance has increased as a result of ODTs. Various clinical trials in a variety of clinical conditions (eg, allergy, psychiatry, migraine headaches) have established an increase in compliance to dosing regimens for medications delivered via ODT. ${ }^{12}$ Patients report that the ODTs were well-tolerated and just as effective as conventional tablets.

Patient preference may influence compliance. It has been reported that, for easy swallowing, the optimal tablet size should not exceed $8 \mathrm{~mm}$. For ease of tablet handling, however, the size should be greater than $8 \mathrm{~mm},{ }^{11}$ resulting in a tension between ease of handling and ease of swallowing. ODTs overcome this paradox by eliminating the need for swallowing and the size may contribute to patient preference.

\section{Vardenafil orally disintegrating tablet}

Vardenafil ODT (scheduled for release in the United States in 2011) carries the indication for treatment of $E D$ and is generally taken up to 1 hour before sexual activity. Vardenafil ODT shares many positive attributes with other ODTs. Its unique blister-pack packaging protects the structural integrity of the tablet and retards excessive humidity. Packaging in boxes of 4 tablets with easy opening peel-back containers is easier to handle than tamper-proof bottles, especially if the individual has arthritic hands or other impairments. Because of the package size, the product can be transported in original containers another important safety feature. Film-coated tablets offer the opportunity to remove the product from the tamper-proof container and store it in a pocket or other container. Safety experts generally agree that leaving the product in its original packaging ensures accurate product identification.

The pharmacokinetics of vardenafil ODT, compared with the standard film-coated pill dosage form, demonstrates a higher systemic exposure. The time to reach $\mathrm{C}_{\max }$ was 1.5 hours and was $15 \%$ higher than the film-coated tablet. There appears to be no effect on peak onset after consumption of high fat meals. However, swallowing the ODT with water has reduced the area under the curve (AUC) by $29 \%$.

\section{Efficacy and safety}

The POTENT I and POTENT II studies, conducted in more than 30 centers around the world, provide evidence of the efficacy for vardenafil ODT. Both studies included a fair representation of men over the age of 65 years - notable given the prior under-representation of this age group in other PDE-5 inhibitor studies.

In the POTENT I study, with an enrolled sample of 409 men with ED and 355 completing the study, efficacy was measured using two instruments: the International Index of Erectile Function (IIEF-EF), and two questions (Numbers 2 and 3) from the Sexual Encounter Profile (SEP). ${ }^{13}$ Subjects with ED were recruited into either the less than 65 years age group or the greater than 65 years group. White males comprised the largest number of subjects. Nearly half of all subjects had an organic etiology for ED (Table 2). The study investigators found a statistically significant difference between the vardenafil group and the placebo group $(P<0.0001)$ for all three measures of efficacy (Table 3 ). The incidence and type of adverse event and effect of ODT vardenafil were similar to the film-coated dosage form and the most common adverse effects were headache and flushing (Table 4). No patient deaths were associated with vardenafil ODT. 
Table 2 Demographic data findings from POTENT I and POTENT II

\begin{tabular}{|c|c|c|c|c|c|c|}
\hline \multirow{2}{*}{$\frac{\text { Variable }}{\text { Age }}$} & \multicolumn{2}{|c|}{ POTENT I ${ }^{13}$} & \multicolumn{2}{|c|}{ POTENT II'4 } & \multicolumn{2}{|l|}{ Total } \\
\hline & $<65$ yrs & $\geq 65$ yrs & $<65$ yrs & $\geq 65$ yrs & $<65$ yrs & $\geq 65$ yrs \\
\hline Subjects (n) & 168 & 190 & 170 & 167 & 338 & 357 \\
\hline Race & n (\%) & n (\%) & n (\%) & n (\%) & n (\%) & n (\%) \\
\hline White & $108(64.3)$ & I 32 (69.5) & $107(62.9)$ & I 25 (74.9) & $240(7 I)$ & $232(65)$ \\
\hline Black & $5(3)$ & $9(4.7)$ & $14(8.2)$ & $3(1.8)$ & $14(4.1)$ & $17(4.8)$ \\
\hline Asian & $8(4.8)$ & $5(2.6)$ & $8(4.7)$ & $5(3)$ & $13(3.8)$ & $13(3.6)$ \\
\hline Missing & $47(28)$ & $44(23.2)$ & $4 I(24.1)$ & $34(20.4)$ & 91 (26.9) & $75(21)$ \\
\hline ED type & n (\%) & n (\%) & $\mathrm{n}(\%)$ & n (\%) & n (\%) & n (\%) \\
\hline Organic & $77(48.5)$ & 110 (57.9) & $98(57.6)$ & I2I (72.5) & I 87 (55.3) & $219(61.3)$ \\
\hline Psychogenic & $30(17.9)$ & II (5.8) & $25(14.7)$ & $4(2.4)$ & $4 \mid(12 . I)$ & $29(8.1)$ \\
\hline Mixed & $60(35.7)$ & $68(35.8)$ & $4 I(24.1)$ & $38(22.8)$ & $128(37.9)$ & $79(22.1)$ \\
\hline Missing & I $(0.6)$ & I $(0.5)$ & $6(3.5)$ & $4(2)$ & $2(0.6)$ & $10(2.8)$ \\
\hline
\end{tabular}

Researchers involved in the POTENT II study conducted a double-blind, multicenter, randomized, parallel-group, placebo-controlled study in four countries. ${ }^{14}$ Data were collected from 331 subjects with more than $50 \%$ of the sample being over the age of 65 years. Predominantly, white males and men with organic ED were represented in the sample. Efficacy was measured using the International Index of Erectile Function (IIEF-EF) as well as portions of the Sexual Encounter Profile. Statistically significant treatment effects were noted when comparing vardenafil group and the placebo group $(P<0.0001)$. As in the POTENT I study, side effects and adverse events were similar between the ODT vardenafil and the film-coated dosage form and differed from placebo. Headache and flushing were the most commonly reported adverse effects. By the end of the 12-week study period, there were no notable differences among a number of physiological variables such as vital signs (including blood pressure), ECG changes, or other laboratory measures. ${ }^{14}$

\section{Patient counseling: an essential safety element}

Clinicians must be comfortable addressing ED with patients, and in some cases, must wait for cues from the patient., Clinicians have an important role in providing information

Table 3 POTENT I and POTENT II efficacy findings at I 2 weeks by mean scores

\begin{tabular}{llllll}
\hline Efficacy & \multicolumn{2}{l}{ POTENT II3 } & & \multicolumn{2}{l}{ POTENT II' } \\
\cline { 2 - 3 } \cline { 5 - 6 } & Placebo & $\begin{array}{l}\text { Vardenafil } \\
\text { ODT }\end{array}$ & & Placebo & $\begin{array}{l}\text { Vardenafil } \\
\text { ODT }\end{array}$ \\
\hline IIEF-EF & 14.4 & $21.5^{*}$ & & 15.0 & $22.9^{*}$ \\
SEP \# 2 & 46.7 & $73.7^{*}$ & & 48.8 & $76.1^{*}$ \\
SEP \# 3 & 26.7 & $64.9^{*}$ & & 30.7 & $69.6^{*}$ \\
\hline
\end{tabular}

Note: *Difference in mean scores statistically significant $(P<0.000 I)$.

Abbreviations: IIEF-EF, International Index of Erectile Function; SEP, Sexual Encounter Profile. about vardenafil ODT to ED patients. One of the most important roles of the clinician is to ensure that patients recognize that the $10 \mathrm{mg}$ vardenafil ODT is not interchangeable with the $10 \mathrm{mg}$ vardenafil film-coated tablet as there are slight differences in pharmacokinetics. Should patients not experience sufficient outcomes with the ODT formulation, the film-coated tablet dosage form should be explored.

As with other PDE-5 inhibitor agents, there is a safety profile that should be understood by the patient and the clinician. This safety profile includes the thorough medical history, physical exam, a complete medication reconciliation, and assessment of risk factors. Clinicians should recognize that structural deformities of the penis (eg, Peyronie's disease) are contraindications to this product class. Concomitant medications (Table 5) that have untoward pharmacodynamic effects include nitrates (absolute contraindication), alpha-blockers, antihypertensives, and potent CYP3A4 inhibitors (cautions with regard to concomitant administration).

Patients should receive counseling on adverse effects. General adverse reactions have been reported with vardenafil ODT and mirror many adverse effects from PDE-5 inhibitors. The most common adverse reactions were headache, flushing, nasal congestion, dyspepsia, dizziness, and back pain. It is unknown if analgesia or antipyretic use prior to administering vardenafil ODT would reduce adverse effects.

Table 4 Leading adverse events ${ }^{\mathrm{a}}$ from POTENT I and POTENT II

\begin{tabular}{|c|c|c|c|c|}
\hline \multirow[t]{2}{*}{ Adverse event } & \multicolumn{2}{|c|}{ POTENT |'3 } & \multicolumn{2}{|c|}{ POTENT II' } \\
\hline & Placebo & $\begin{array}{l}\text { Vardenafil } \\
\text { ODT }\end{array}$ & Placebo & $\begin{array}{l}\text { Vardenafil } \\
\text { ODT }\end{array}$ \\
\hline Headache & 2 & 30 & 4 & 21 \\
\hline Flushing & 0 & 14 & 2 & 13 \\
\hline Nasal congestion & 0 & 3 & I & 8 \\
\hline Dyspepsia & 0 & 7 & 0 & 3 \\
\hline
\end{tabular}

Note: ${ }^{\text {In }}$ patients reporting more than $1 \%$ adverse events. 
Table 5 Significant drug:drug interactions with PDE-5 agents

\begin{tabular}{ll}
\hline Drug class $^{15}$ & Potential serious adverse effects \\
\hline Alpha blockers & Hypotension \\
Nitrates & Hypotension, myocardial infarction, shock \\
Antihypertensives & Additive effects; may see $0-10 \mathrm{mmHg}$ reduction \\
CYP3A4 inhibitors & Increases vardenafil levels \\
\hline
\end{tabular}

Patients should be healthy enough for sexual activity. Patients with significant unstable angina, hypotension, severe cardiac failure, recent stroke, or recent myocardial infarction $^{15}$ must refrain from sexual activity until the condition is stable and allows physical exercise/sexual activity. From the genitourinary system, there is the recognition of risk for priapism (painful erection of more than 4 hours' duration). A sudden loss of vision in one or both eyes warrants prompt evaluation, as does the sudden loss of hearing. With the emerging use and availability of many homeopathic and herbal supplements, patients must receive counseling to avoid combining various therapies in order to avoid potentiating adverse effects. Consumers who use vardenafil ODT should also recognize that the product affords no protection against sexually transmitted infections.

Patients should also be counseled on several other topics. For examples, the desirable effects of increased erection, quality, strength, and ejaculate should be anticipated. Patients should receive instruction on how to take the ODT, which is placed on the tongue and rapidly dissolves. Patients should not remove the medication from the original blister pack until ready to take - a major benefit of the packaging of vardenafil ODT. They should also be taught to avoid taking the medication with water as previously mentioned.

\section{Summary}

Today, numerous treatment options exist for ED; many are mechanical in nature and some are pharmaceutical. The pharmaceutical approach to ED has been well studied and appears to be well tolerated and should be the first-line therapeutic approach. This approach is also less invasive. As the broad range of patients who experience some form of ED materializes, clinicians will need a good knowledge of the wide range of treatment options ${ }^{4}$ as well as the safety and efficacy features of these options.

Vardenafil ODT is an important agent to treat ED. Because of the ease of use, ODTs will help men find an acceptable and appropriate treatment option.

\section{Disclosure}

The authors declare no conflicts of interest.

\section{References}

1. Green R, Kodish S. Discussing a sensitive topic: nurse practitioners' and physician assistants' communication strategies in managing patients with erectile dysfunction. J Am Acad Nurse Pract. 2009;21(12):698-705.

2. Shabsigh R, Perelman MA, Laumann EO, Lockhart DC. Drivers and barriers to seeking treatment for erectile dysfunction: a comparison of six countries. BJU Int. 2004;94(7):1055-1065.

3. McKinlay JB. The worldwide prevalence and epidemiology of erectile dysfunction. Int J Impot Res. 2000;12(Suppl 4):S6-S11.

4. Hatzichristou DG, Pescatori ES. Current treatments and emerging therapeutic approaches in male erectile dysfunction. BJU Int. 2001; Suppl 3:11-17.

5. Dean RC, Lue TF. Physiology of penile erection and pathophysiology of erectile dysfunction. Urol Clin North Am. 2005;32(4):379-395, v.

6. Lewis JH, Rosen R, Goldstein I. Erectile dysfunction. Am J Nurs. 2003; 103(10):48-57, quiz 57-48.

7. McCance KL, Huether SE, Brashers VL, Rote NS. Pathophysiology: The Biologic Basis for Disease in Adults and Children. 6th ed. St. Louis: Mosby; 2010.

8. Cranwell-Bruce LA. Drugs for erectile dysfunction. MEDSURG Nursing. 2010;19(3):185-191

9. The United States Pharmacoepeial Convention. $<1151>$ Pharmaceutical dosage forms. Pharmacopeial Forum. 2009;35(5):1271-1305.

10. European Pharmacopeia. Tablets. Ed 4. 2002;Suppl 4(2):2435.

11. Hirani JJ, Rathod DA, Vadalia KR. Orally disintegrating tablets: a review. Tropic Journal of Pharmaceutical Research. 2009;8(2):161-172.

12. Fu Y, Yang S, Jeong SH, Kimura S, Park K. Orally fast disintegrating tablets: developments, technologies, taste-masking and clinical studies. Crit Rev Ther Drug Carrier Syst. 2004;21(6):433-476.

13. Sperling H, Debruyne F, Boermans A, Beneke M, Ulbrich E, Ewald S. The POTENT I randomized trial: efficacy and safety of an orodispersible vardenafil formulation for the treatment of erectile dysfunction. $J$ Sex Med. 2010;7(4 Pt 1):1497-1507.

14. Gittelman M, McMahon CG, Rodriguez-Rivera JA, Beneke M, Ulbrich E, Ewald S. The POTENT II randomised trial: efficacy and safety of an orodispersible vardenafil formulation for the treatment of erectile dysfunction. Int J Clin Pract. 2010;64(5):594-603.

15. Douglass MA, Lin JC. Erectile dysfunction and premature ejaculation: underlying causes and available treatment. Formulary. 2010;45: $17-27$.
Patient Preference and Adherence

\section{Publish your work in this journal}

Patient Preference and Adherence is an international, peer-reviewed, open access journal focusing on the growing importance of patient preference and adherence throughout the therapeutic continuum. Patient satisfaction, acceptability, quality of life, compliance, persistence and their role in developing new therapeutic modalities and compounds to

\section{Dovepress}

optimize clinical outcomes for existing disease states are major areas of interest. This journal has been accepted for indexing on PubMed Central. The manuscript management system is completely online and includes a very quick and fair peer-review system. Visit http://www.dovepress.com/ testimonials.php to read real quotes from published authors. 